\title{
Influence of Welding Materials of Duplex Current Feeding MIG Welding*
}

\author{
by AOKI Atsuhito**, TASHIRO Shinichi***, KUROKAWA Hideaki**** and TANAKA Manabu***
}

\begin{abstract}
The duplex current feeding metal inert gas (DCF-MIG) welding which has two current feeding points was developed. This DCF-MIG process is able to control the welding current and wire feeding speed independently by additional feeding current from the secondary tip below the conventional MIG tip. In the past DCF-MIG studies, only the studies using the steel or SUS welding wire material were reported. In this study, the influence of welding wire materials of DCF-MIG was investigated. As a result, the electrical conductivity of welding wire materials was found to have influence on the quantity of Joule heating between current feeding points. However, in the DCF-MIG with low electrical conductivity material, the average of primary current greatly decreases as the increase of the secondary current, consequently the total current of DCF-MIG was suppressed. It was found that there was the optimum value of electrical conductivity of welding material to obtain enough effects of DCF-MIG.
\end{abstract}

Key Words: Pure Ar MIG, Duplex current feeding, Droplet heat content, Welding materials

\section{Introduction}

In order to guarantee safety of cryogenic service structure such as Liquefied Natural Gas (LNG) tanks, it is necessary to achieve both high strength and enough toughness of the welded joint ${ }^{1)}$. However, the toughness of the weld metal of stainless steel or nickel based alloy, which are often used for cryogenic structure, tend to decrease due to oxygen contamination during welding ${ }^{2)}$.

Therefore, Tungsten Inert Gas (TIG) Welding is applied in many structures for cryogenic service. Though TIG produces a high quality weld joint, it has a disadvantage of lower welding efficiency. On the other hand, Metal Inert Gas (MIG) Welding realizes higher welding efficiency in comparison with TIG. MIG under pure $\mathrm{Ar}$ shielding gas atmosphere (pure Ar MIG) is called "Clean MIG", which is recently attracting a lot of attention ${ }^{1)}$. However, Clean MIG has some drawbacks. It faces welding quality problems such as meandering weld bead due to the unstable arc ${ }^{3)}$, convex weld bead due to high surface tension of the molten metal ${ }^{4)}$ and shallow penetration due to insufficient heat input.

Concerning these pure Ar MIG problem, various solutions have been reported. For example, Nakamura et al. developed a coaxial hybrid wire composed of an outer shell with a high melting point and a core metal with a low melting point ${ }^{3}$. Zenitani et al. introduced a process which used the shielding gas added minimum amount of oxygen necessary to stabilize the arc ${ }^{5}$. Tanaka et al. reported that the plasma MIG welding process has the ability to stabilize the MIG arc ${ }^{6}$. These studies presented improved arc

${ }^{*}$ Received: 2019.11.21, Presented at Visual-JW

** Member, Kawasaki Technology Co., Ltd.

*** Member, Joining and Welding Research Institute Osaka University

${ }^{* * * *}$ Member, Kawasaki Heavy Industries, Ltd. stability in the Clean MIG process. However, the latter problem of Clean MIG, i.e., convex weld bead, has not yet been solved. A convex weld bead is caused by a high surface tension due to low oxygen content in the molten metal. The oxygen in the molten metal is effective in reducing surface tension. However, in Clean MIG, this effect cannot be expected. Therefore, one solution is to increase the heat input to the molten metal to reduce the surface tension. However, due to the unique relationship between the welding current and the wire feed speed in MIG welding process, it is difficult to increase the heat content of droplets independently.

In order to obtain both arc stability and a good bead shape using Clean MIG process, a MIG welding process with a duplex current feeding (DCF-MIG) has been developed ${ }^{7-9}$. The DCF-MIG welding process can control the welding current and the wire feeding speed independently by an additional current fed from a secondary power source. The secondary current feeding point is located below the MIG contact tip which feeds the primary current. Aoki et al. have clarified the basic characteristics of DCF-MIG with steel wire.

In this study, experiments were conducted to clarify the basic characteristic of DCF-MIG with various welding materials which have different electrical conductivity, for example from high electrical conductivity such as aluminum to low electrical conductivity such as nickel based alloy.

Moreover, in order to apply the DCF-MIG to practical cryogenic structures, the DCF-MIG characteristics of stainless steel wire and nickel based alloy (Inconel 625) wire are examined.

\section{Experimental procedure}

\subsection{DCF-MIG Experimental system}


The structure of the DCF-MIG torch is shown in Fig. 1. The basic device configuration was almost the same as that of previous studies ${ }^{7-9)}$. There are two current feeding points which are insulated by ceramic to avoid current conduction. The torch is equipped with double gas flow structure for the center gas and the shielding gas. The composition of both gas flows is $100 \% \mathrm{Ar}$ (pure Ar). In addition, the outer nozzle was installed around the DCFMIG torch to feed pure Ar to prevent the bead from oxidation. The distance of feeding points was $12 \mathrm{~mm}$. The primary current fed at the primary feeding point is pulse current and is supplied by a welding power source with constant voltage characteristics, which corresponds to the MIG current in conventional MIG welding. The secondary current fed at the secondary feeding point is DC waveform and is supplied by a welding power source with constant current characteristics.

The experiment was conducted using a welding robot equipped with a DCF-MIG torch, as shown in Fig. 2. The voltage waveforms for the primary and secondary currents were collected by a data logger. The current waveforms were also collected by the data logger through clamp meters. The time resolution of the data collection was $0.1 \mathrm{msec}$ to acquire the welding current pulse accurately which has a duration of several milliseconds.

Various types of calorimeters are being used for measuring temperature or droplet heat content ${ }^{10)}$. Fig. 3 shows the calorimeter to measure droplet heat content in this study. The calorimeter consists of a Dewar vessel covered by heat insulation as a water bath, a copper crucible that catches the droplets, a magnetic stirrer to stir the water, and thermocouples (type $\mathrm{K}$ ) which measure the temperature of the water, the crucible and the air in the Dewar vessel. The rotational speed of the stirrer is set to $250 \mathrm{rpm}$. The collection sampling time of temperature data is set to $50 \mathrm{msec}$. In the calorimetric experiment, a water-cooled doughnut cathode is used. The doughnut hole allows the passage of the detached droplets into the copper crucible. The quantity of the water to which heat of droplet was transferred was $1000 \mathrm{~g}$.

\subsection{Welding materials}

Table 1 shows the welding materials in this study. Spooled welding wires with diameter $1.2 \mathrm{~mm}$ were used in the experiment. Electrical conductivities were shown in Table 1. Electrical conductivity of aluminum wire is higher than that of steel wire, on the other hand SUS308 wire and Inconel 625, which is nickel based alloy are far lower than that of steel wire.

\subsection{Welding conditions}

The distance from the lower edge of the primary contact tip to the work surface (herein referred to as CTWD: contact tip to work

distance) was fixed to $30 \mathrm{~mm}$. In the case except aluminum wire, length between primary contact tip and secondary contact tip was $12 \mathrm{~mm}$ and the distance from the lower edge of the secondary tip to the work surface was $18 \mathrm{~mm}$. In the case of aluminum wire, length between primary contact tip and secondary contact tip was $14.5 \mathrm{~mm}$ and the distance from the lower edge of the secondary tip to the work surface was $15.5 \mathrm{~mm}$. The contact thickness of secondary contact tip is $1 \mathrm{~mm}$.

Wire feeding speed was fixed to $8 \mathrm{~m} / \mathrm{min}$. In the case of aluminum wire, the primary power source mode was set to the "MIG hard aluminum wire" mode and setting current was $145 \mathrm{~A}$. In the case of steel wire, the primary power source mode was set to the "MAG mild steel solid wire" mode and setting current is 207 A. In the case of SUS308 and Inconel 625 wire, "MIG Stainless solid wire" mode was set and setting current was $148 \mathrm{~A}$.

The primary power source controls arc length by pulse frequency modulation. For example, when the arc length is long (e.g., arc voltage is high), the power source stretches the period of

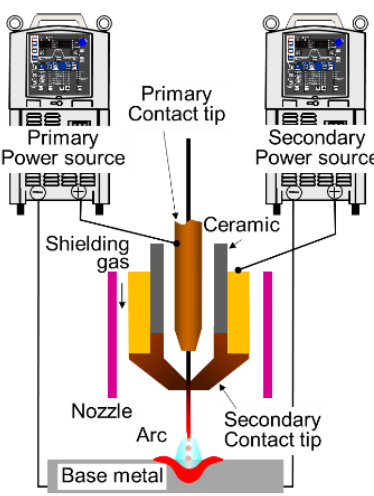

Fig. 1 Schematic diagram of DCF-MIG.

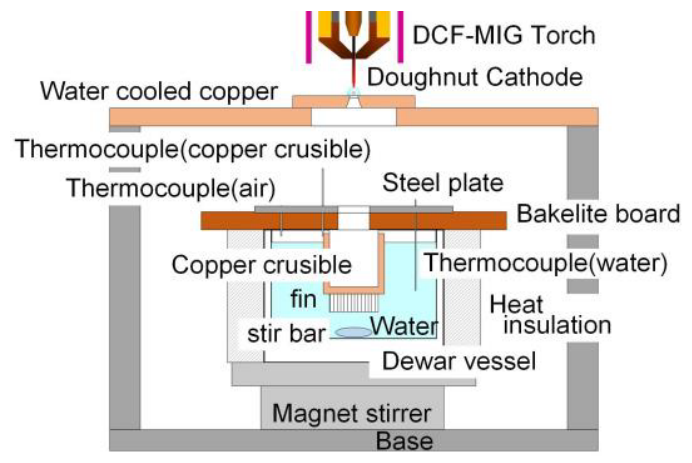

Fig. 3 Calorimeter.

Table 1 Welding wire material specification

\begin{tabular}{|l|l|c|}
\hline $\begin{array}{c}\text { Wire } \\
\text { material }\end{array}$ & $\begin{array}{l}\text { JIS code } \\
\text { of welding wire }\end{array}$ & $\begin{array}{c}\mathbf{2 0}^{\circ} \mathrm{C} \text { Electrical } \\
\text { Conductivity }\end{array}$ \\
\hline Aluminum & Z 3232 A5183-WY & $17.98 \times 10^{6} \mathrm{~S} / \mathrm{m}$ \\
\hline Steel & Z 3312 G 49 AP 3 M 16 & $7.04 \times 10^{6} \mathrm{~S} / \mathrm{m}$ \\
\hline SUS308 & Z 3321 YS308 & $1.39 \times 10^{6} \mathrm{~S} / \mathrm{m}$ \\
\hline Inconel 625 & Z 3334 GNi6625 & $0.78 \times 10^{6} \mathrm{~S} / \mathrm{m}$ \\
\hline
\end{tabular}


Table 2 Welding conditions for bead on plate welding.

\begin{tabular}{|c|c|c|c|c|}
\hline $\begin{array}{l}\text { Welding } \\
\text { Materials }\end{array}$ & $\begin{array}{l}\text { Welding } \\
\text { speed }\end{array}$ & $\begin{array}{l}\text { Wire } \\
\text { feeding } \\
\text { speed }\end{array}$ & $\begin{array}{l}\text { Primary } \\
\text { pow.src. } \\
\text { voltage }\end{array}$ & $\begin{array}{l}\text { Secondary } \\
\text { setting } \\
\text { current }\end{array}$ \\
\hline Aluminum & \multirow{4}{*}{$\begin{array}{l}30 \\
\mathrm{~cm} / \mathrm{min} .\end{array}$} & \multirow{4}{*}{${ }^{8} \mathrm{~m} / \mathrm{min}$} & $\begin{array}{l}18 \sim 22 \mathrm{~V} \\
\end{array}$ & \multirow{4}{*}{$\begin{array}{l}\text { O(Conv.MIG), } \\
25,50, \\
75,100 \mathrm{~A}\end{array}$} \\
\hline Steel & & & $28 \sim 29 \mathrm{~V}$ & \\
\hline SUS308 & & & $25 \sim 29 \mathrm{~V}$ & \\
\hline Inconel625 & & & $20 \sim 27 \mathrm{~V}$ & \\
\hline
\end{tabular}

Table 3 Welding conditions for calorimetry.

\begin{tabular}{|l|l|l|l|}
\hline $\begin{array}{l}\text { Welding } \\
\text { Materials }\end{array}$ & $\begin{array}{l}\text { Wire } \\
\text { feeding } \\
\text { speed }\end{array}$ & $\begin{array}{l}\text { Primary } \\
\text { pow.src. } \\
\text { voltage }\end{array}$ & $\begin{array}{l}\text { Secondary } \\
\text { setting } \\
\text { current }\end{array}$ \\
\hline Aluminum & $13 \mathrm{~m} / \mathrm{min}$ & $25 \sim 27 \mathrm{~V}$ & $0,25,50 \mathrm{~A}$ \\
\hline Steel & & $25 \sim 27 \mathrm{~V}$ & 0 (Conv.MIG), \\
\cline { 1 - 1 } SUS308 & $8 \mathrm{~m} / \mathrm{min}$ & $26 \sim 28 \mathrm{~V}$ & 25,50, \\
\cline { 1 - 1 } Inconel625 & & $23 \sim 27 \mathrm{~V}$ & $75,100 \mathrm{~A}$ \\
\hline
\end{tabular}

the pulse base, which causes a decrease in the average of the pulse current. Then, the wire melting rate becomes low and the arc length shortens.

In order to analyze the effect of DCF-MIG on different type of welding materials, bead-on-plate welding was carried out. The bead-on-plate welding conditions are shown in Table 2.The voltage of the primary power source was set to keep the same arc length of about $4 \mathrm{~mm}$ and to prevent a short circuit transfer in all the experiments. In the aluminum experiment, the base metal was A5083-O with a $10 \mathrm{~mm}$ thickness. Except aluminum experiments, the base metal was mild steel (JIS SS400) with a $12 \mathrm{~mm}$ thickness and its surface scale was removed by a grinder.

In the experiment using the calorimeter, the DCF-MIG torch was kept stable. The welding conditions are shown in Table 3. The voltage of the primary power source was set to keep the same arc length of about $4 \mathrm{~mm}$. In order to increase collected mass of aluminum, the wire feeding speed was raised.

\section{Result and discussion}

\subsection{Current increase effect of DCF-MIG}

Fig. 4 shows the average values of the total current, which is the sum of the primary current (lower bar) and the secondary current (upper bar) as a function of the secondary current and welding materials. This data was measured in bead-on-plate experiments. The primary current decreased and the total current increased as the secondary current increased except aluminum wire. In the case of aluminum wire, total currents were almost the same. Furthermore, the total current of DCF-MIG was always larger than that of the conventional MIG.

However, a rate of decline of the primary current varied according to welding materials. Table 4 shows rates of increase of the total current and the secondary current and a rate of decline of the primary current. The difference of decreasing rate of the

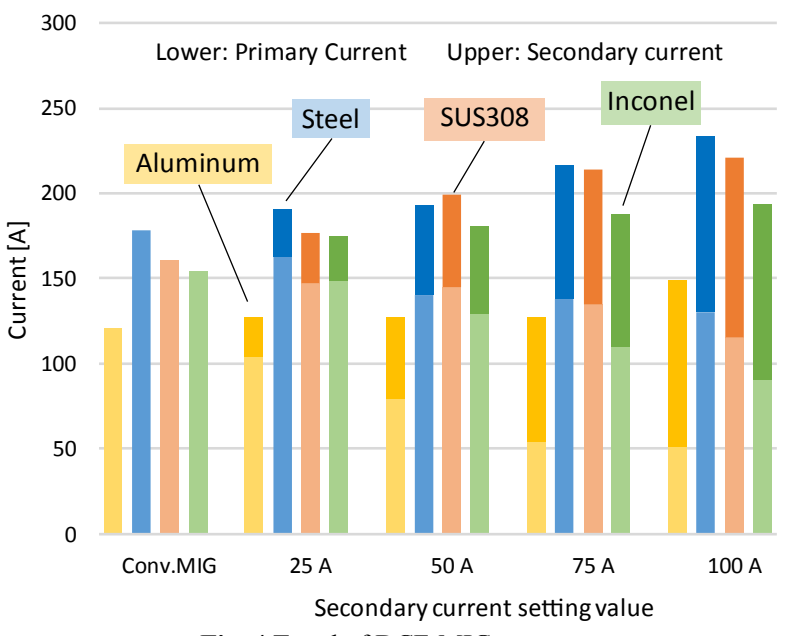

Fig. 4 Trend of DCF-MIG current.

Table 4 Ratio of change of currents.

\begin{tabular}{|l|c|c|c|}
\hline \multirow{2}{*}{$\begin{array}{l}\text { Wire } \\
\text { material }\end{array}$} & \multicolumn{3}{|c|}{ Ratio of change } \\
\cline { 2 - 4 } & Trend of measured current against 2nd current \\
\hline Aluminum & 0.26 & -0.74 & 1.00 \\
\hline Steel & 0.68 & -0.32 & 1.00 \\
\hline SUS308 & 0.49 & -0.52 & 1.02 \\
\hline Inconel625 & 0.24 & -0.78 & 1.02 \\
\hline
\end{tabular}

1.2

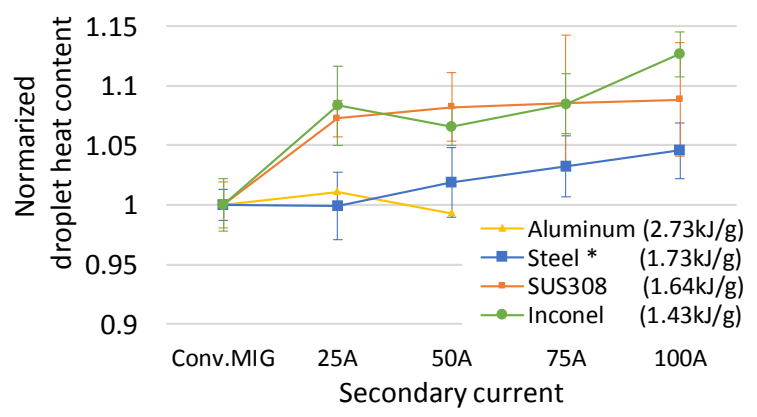

Fig. 5 Normalized droplet heat content. * Steel data 8) $(* \mathrm{~kJ} / \mathrm{g})$ is heat content of conventional MIG

primary current is caused by the difference of electrical conductivity of welding materials, which are shown in Table 1, and by the difference of power source characteristic. The low electrical conductivity causes large voltage drop at the secondary feeding point of DCF-MIG torch and wire extension. For example of Inconel 625 wire which has low electrical conductivity, the voltage drop was large, then the primary current dropped greatly in comparison with steel wire or SUS308 wire. In the case of aluminum, though the electrical conductivity is large, the drop of the primary current was large. It is thought that the low melting point of aluminum influences this.

These results show that the DCF-MIG has the effect of increasing welding current for various welding materials.

\subsection{Droplet heat content}


Next, the effect of DCF-MIG for droplet heat content was investigated by using the calorimetry.

Fig. 5 shows the normalized droplet heat content measured by calorimetry. The measured values were normalized by the heat content value of conventional MIG of each welding material.

Except aluminum wire, there is increasing tendency of droplet heat content as the secondary current increase. On the other hand, the droplet heat content of aluminum wire was almost the same as increase of secondary current. This tendency of heat content is similar to that of current of aluminum wire. The droplet heat contents of SUS308 and Inconel 625 wire were larger than that of conventional MIG even the secondary current was only $25 \mathrm{~A}$.

\subsection{Discussion of droplet heat content}

In this section the energy balance of DCF-MIG wire is discussed through a simplified calculation.

The relationship between wire melting speed $V_{m}[\mathrm{~mm} / \mathrm{sec}]$ and the droplet heat content $H_{0}\left[\mathrm{~J} / \mathrm{mm}^{3}\right]$ is represented by the below equation of Halmoy ${ }^{11)}$.

$$
V_{m}=\frac{1}{H_{0}+b}\left(\phi j+a L j^{2}\right)
$$

where $\phi[\mathrm{V}]$ is the equivalent voltage of melting anode by arc, $j$ $\left[\mathrm{A} / \mathrm{mm}^{2}\right]$ is the effective current density, $L[\mathrm{~mm}]$ is the wire extension, $a[\Omega \cdot \mathrm{mm}]$ is the constant of specific resistance of wire, and $b\left[\mathrm{~J} / \mathrm{mm}^{3}\right]$ is the constant depending on the specific resistance. Eq. (2) is obtained by solving Eq. (1) for $H_{0}$ :

$$
H_{0}=\frac{\phi j}{V_{m}}+\left(\frac{a L j^{2}}{V_{m}}-b\right) \text {. }
$$

Here, the first term on the right side of Eq. (2) indicates the heat input from the arc. The second term indicates Joule heating, which is the first order approximation of experimental data from the fourterminal sensing.

Considering the torch structure of DCF-MIG, the primary current $I_{l}$ flows through the section $\left(L_{l}\right)$ from the primary feeding point to the secondary feeding point. Through the section $\left(L_{2}\right)$ from the secondary feeding point to the tip of the wire, the total current $I_{12}$, which is the sum of the primary current $I_{l}$ and the secondary current $I_{2}$ flows. Here, currents $I_{1}$ and $I_{12}$ are divided by a wire cross-sectional area to calculate current density $j_{1}$ and $j_{12}$. Then, Eq. (3) is derived by expanding Eq. (2). The term of Joule heating on the section between the feeding points is added as follows:

$$
H_{0}=\frac{\phi j_{12}}{V_{m}}+\left(\frac{a_{1} L_{1} j_{1}^{2}}{V_{m}}-b\right)+\left(\frac{a_{12} L_{2} j_{12}^{2}}{V_{m}}\right) .
$$

Because $L_{2} j_{12}{ }^{2} / V_{m}$ of the third term of Eq. (3) is small, intercept $b$ is assumed to be 0 . Based on the experimental research by Maruo et $\mathrm{al}^{12)}$, material data ${ }^{13-17)}$ and estimated value, the constants of Eq. (3) are shown in Table 5. Except aluminum wire, effective current values used in the calculation were the values measured by

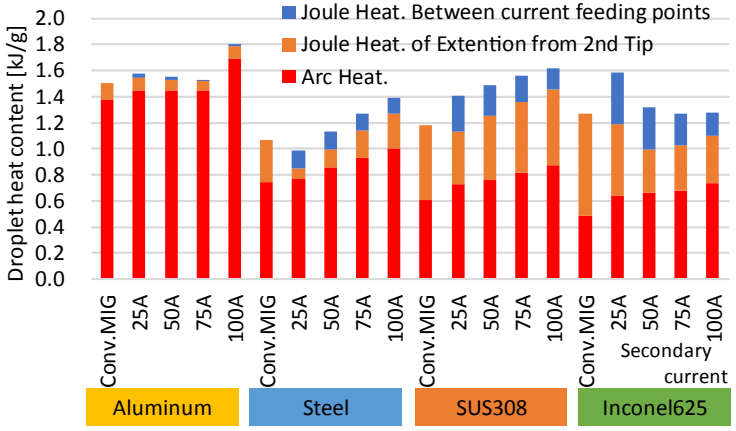

Fig. 6 Calculation of droplet heat content.

Table 5 Coefficients of droplet heat content calculation.

\begin{tabular}{|c|c|c|}
\hline Material & Conventional MIG & $\begin{array}{c}\text { DCF-MIG } \\
\text { 2nd current:100A }\end{array}$ \\
\hline \multicolumn{3}{|l|}{ Aluminum } \\
\hline \multicolumn{3}{|l|}{ Steel $^{8)}$} \\
\hline \multicolumn{3}{|l|}{ SUS308 } \\
\hline \multicolumn{3}{|l|}{ Inconel625 } \\
\hline & $\overline{3 \mathrm{~mm}}$ & $\frac{3 \mathrm{~mm}}{3 \mathrm{~m}}$ \\
\hline
\end{tabular}

\begin{tabular}{|l|r|r|r|r|}
\hline & \multicolumn{1}{|c|}{ Aluminum } & \multicolumn{1}{c|}{ Steel } & \multicolumn{1}{c|}{ SUS308 } & Inconel625 \\
\hline$\phi[\mathrm{V}]$ & 5.1 & 5.7 & 5.3 & 5.3 \\
\hline$V_{m}[\mathrm{~mm} / \mathrm{sec}]$ & 133.3 & 133.3 & 133.3 & 133.3 \\
\hline$a_{1}\left[10^{-4} \Omega \mathrm{m}\right]$ & 1.70 & 9.40 & 11.60 & 13.50 \\
\hline$L_{1}[\mathrm{~mm}]$ & 14.5 & 12 & 12 & 12 \\
\hline$b\left[\mathrm{~J} / \mathrm{mm}^{3}\right]$ & 0.00 & 1.92 & 0.97 & 0.00 \\
\hline$a_{12}\left[10^{-4} \Omega \mathrm{m}\right]$ & 0.56 & 3.97 & 8.33 & 13.20 \\
\hline$L_{2}[\mathrm{~mm}]$ & 11.5 & 14 & 14 & 14 \\
\hline
\end{tabular}

Table 6 Cross section of bead

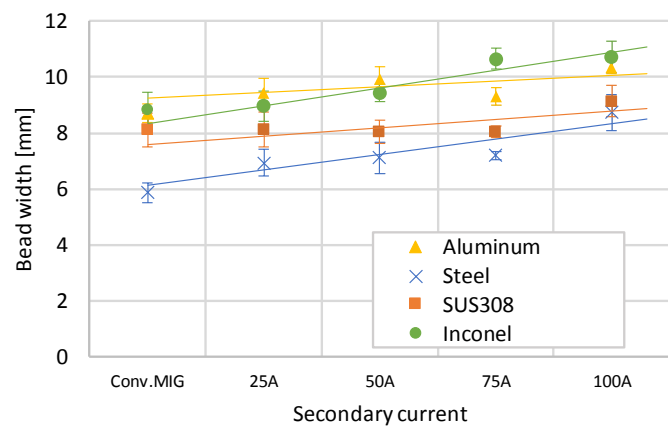

Fig. 7 Measured bead width on secondary current.

calorimetry. In the aluminum wire, that were the values measured by bead-on-plate experiment.

Fig. 6 shows the calculation results on welding materials and the secondary current obtained using Eq. (3). The upper part of bar graph represents Joule heating between the primary feeding point and the secondary feeding point, the middle part of bar represents Joule heating in wire extension, and the lower part of bar represents the arc heating. 
The tendency of measured droplet heat content and calculated value is similar. The result of low conductivity materials (SUS308, Inconel 625) shows that the contribution of Joule heating is large. In the aluminum wire, the Joule heating had little contribution and calculated values are almost the same.

In the case of Inconel 625 wire, calculated heat content of secondary current 25 A was remarkably high. And this phenomenon is also shown in the experimental value (Fig. 5). The reason of this is considered that where the secondary current is over $50 \mathrm{~A}$, due to the large decline of the primary current, pulse period was extended. Then the effective current decreased largely and the droplet heat content resulted in small value relatively.

\subsection{Bead shape}

The influence of increased current and droplet heat content of DCF-MIG on the bead shape was investigated.

Table 6 shows the cross sections of bead of conventional MIG, and DCF-MIG with secondary current $100 \mathrm{~A}$. It is found that in all materials, the bead shape such as penetration and wettability was improved. And Fig. 7 shows the measured bead width. In all materials, the increase of bead width as increase of secondary current was observed. However increase effect of aluminum wire was little.

Moreover, though the total current of DCF-MIG increased monotonously as the secondary current increase, the increase rate of bead width is not constant. One reason of this is that droplet heat content did not increase constantly. Another reason is material characteristic such as viscosity of molten material. Furthermore, it is considered that preheating effect by the arc also makes contribution to the improvement of the bead wettability.

\section{Conclusions}

In this study, the influence of welding material was investigated experimentally. The conclusions are summarized as follows:

1) It is found that the total current increase effect of DCF-MIG was observed concerning steel, SUS308 and Inconel 625 wire but that for aluminum was little.

2) The electrical conductivity of welding materials has great influence on the total current of DCF-MIG and droplet heat content, i.e. in the low electrical conductivity material, the total current and droplet heat content of DCF-MIG did not necessarily increase with the increase of secondary current.

3) It is considered that the improvement of bead shape of DCFMIG was not only by the increase of droplet heat content but also by the preheating effect to the base metal.

The characteristics of DCF-MIG of materials used for cryogenic service such as SUS308, Inconel 625 were clarified. In the future, the practical use experiments of DCF-MIG for cryogenic will be conducted.

\section{Reference}

1) KOMIZO Y.: An outline of NEDO project "Fundamental Studies on Technologies for Steel Materials with Enhanced Strength and Functions" J. Jpn Weld. Soc., 78- 6 (2009), 11-14. (in Japanese)

2) O. Kamiya, H. Fujita, T. Enjo, Y. Kikuchi: Oxygen Content and Fracture Toughness on MIG Weld Metal of SUS304 Steel, Quart. J. Jpn Weld. Soc., 3-3 (1985), 574-581. (in Japanese)

3) NAKAMURA T and HIRAOKA K.: GMA Welding of $9 \% \mathrm{Ni}$ steel in the pure Argon shielding gas using coaxial multi-layer solid wire, Quart. J. Jpn Weld. Soc., 30-3 (2012), 254-261. (in Japanese)

4) S.A.David, T.Debroy, J.M.Vitek: Phenomenological Modeling of Fusion Welding Process, MRS Bulletin, 10-1(1994), 29-35.

5) ZENITANI S., NAKAMURA T., HIRAOKA K. and SHINOZAKI K.: Ar-MIG arc Behavior in Local Addition of Small Amount of Oxygen into Shielding Gas, Quart. J. Jpn Weld. Soc., 25-1 (2007) 187-195. (in Japanese)

6) M. Tanaka, T. Tamaki, S. Tashiro, K. Nakata, T. Ohnawa and T. Ueyama: Characteristic of ionized gas metal arc processing, Surf and Coat. Tech., 202 (2008), 5251-5254.

7) SETO M., AOKI A., TANAKA M., TASHIRO S. and ERA T.: Study on new GMA welding process with duplex current feeding, Quart. J. Jpn Weld. Soc., 34-2 (2016), 150-157. (in Japanese)

8) A. Aoki, S. Tashiro, H. Kurokawa, and M. Tanaka: Development of novel MIG welding process with duplex current feeding, J. Mfg. Proc., 47 (2019), 74-82.

9) A. Aoki, S. Tashiro, H. Kurokawa, and M. Tanaka, "Influence of Current Feeding Position of Duplex Current Feeding MIG Welding on Droplet Heat Quantity, Materials, 12-21 (2019), 3590.

10) E Siewert, J Schein and G Forster: Determination of enthalpy, temperature, surface tension and geometry of the material transfer in PGMAW for the system argon-iron, J. Appl. Phys., 46 (2013) 224008 (16pp)

11) E. Halmoy, Wire melting rate, droplet temperature and effective anode melting potential, Proc. Inter. Conf. on Arc Phys. and Weld Pool Behaviour (1979).

12) H. Maruo, Y. Hirata and Y. Noda: Wire Melting Rate in Pulsed MIG Welding - Study on Pulsed Arc Welding (Report 3) -, Quart. J. Jpn Weld. Soc., 3-1 (1985), 191-196. (in Japanese)

13) Sumitomo Metal Industries., Aluminum Handbook (2003), 32-33. (in Japanese)

14) Jpn Inst. Metals and Mat., Metal Handbook rev.5(1990), Maruzen, (in Japanese)

15) Iron and Steel Inst. Jpn, Handbook of Iron and Steel $4^{\text {th }}$ edit. CDROM (2002). (in Japanese)

16) JSSA: Stainless Handbook $3^{\text {rd }}$ edition (1995), Nikkan Kogyo Shimbun. (in Japanese)

17) Special Metals: INCONEL $®$ alloy 625 (2013), https://www.specialmetals.com/assets/smc/documents/alloys/inco nel/inconel-alloy-625.pdf, (18Nov2019). 